\title{
Usefulness of speckle-tracking echocardiography for early detection in children with Duchenne muscular dystrophy: a meta-analysis and trial sequential analysis
}

\author{
Guang Song, Jing Zhang, Xin Wang, Xintong Zhang, Feifei Sun and Xiaona Yu*i)
}

\begin{abstract}
Background: Duchenne muscular dystrophy (DMD) is the most common form of inherited muscle disease in children. The incidence of cardiomyopathy induced by DMD increases with age. Left ventricular ejection fraction usually fails to reflect the subclinical left ventricular dysfunction. Several studies have assessed this dysfunction using myocardial strain measured by speckle-tracking echocardiography (STE). However, the results were inconsistent and incomplete.

Methods: Several databases were searched from their inception to February 5, 2020. The summarized weighted mean difference (WMD) with 95\% confidence intervals (Cls) were estimated for myocardial strain between DMD and healthy controls and a meta-analysis was conducted. Trial sequential analysis estimated whether the resulting evidence was sufficient.

Results: Eight studies with a total of 269 DMD children and 299 healthy participants were included. STE revealed that global longitudinal strain (GLS), global circumferential strain, average longitudinal strain (measured by twodimensional STE at the apical four-chamber view), and average circumferential strain (measured by two-dimensional STE at the papillary muscle short-axis level) decreased (WMD $=4.17,95 \% \mathrm{Cl}: 3.03-5.32$; WMD $=3.98,95 \%$ Cl: $0.29-$ 7.68; $\mathrm{WMD}=4.18,95 \% \mathrm{Cl}: 2.75-5.62$; and $\mathrm{WMD}=4.90,95 \% \mathrm{Cl}: 2.38-7.43$, respectively; all $P<0.05)$ compared with the controls and global radial strain was unchanged in the DMD group (WMD $=-4.33,95 \% \mathrm{Cl}$ : $-9.53-0.87, P=$ 0.103). Trial sequential analysis indicated that available GLS samples were sufficient and confirmed that adequate evidence was accumulated. The credibility of other myocardial strains was questioned due to insufficiently involved studies.
\end{abstract}

Conclusion: GLS can be useful for early detection of left ventricle myocardial dysfunction in children with DMD. Keywords: Cardiomyopathy, Duchenne muscular dystrophy, Pediatrics, Speckle-tracking echocardiography, Strain

\footnotetext{
*Correspondence: yuxn13756@163.com

Department of Ultrasound, Shengjing Hospital of China Medical University,

36 Sanhao St, Heping District, Shenyang 110001, Liaoning Province, China
}

(c) The Author(s). 2020 Open Access This article is licensed under a Creative Commons Attribution 4.0 International License, which permits use, sharing, adaptation, distribution and reproduction in any medium or format, as long as you give appropriate credit to the original author(s) and the source, provide a link to the Creative Commons licence, and indicate if changes were made. The images or other third party material in this article are included in the article's Creative Commons licence, unless indicated otherwise in a credit line to the material. If material is not included in the article's Creative Commons licence and your intended use is not permitted by statutory regulation or exceeds the permitted use, you will need to obtain permission directly from the copyright holder. To view a copy of this licence, visit http://creativecommons.org/licenses/by/4.0/ The Creative Commons Public Domain Dedication waiver (http://creativecommons.org/publicdomain/zero/1.0/) applies to the data made available in this article, unless otherwise stated in a credit line to the data. 


\section{Introduction}

Duchenne muscular dystrophy (DMD) is an X-linked recessive disorder caused by the lack of dystrophin encoded by the $D M D$ gene. It is the most common form of inherited muscle disease in children [1]. DMD is a severe disease with muscular dystrophy that begins at the age of about 7 years and then rapidly and progressively leads to a loss of independent ambulation by the age of 12 years, followed by scoliosis, loss of upper limb function, respiratory insufficiency, or cardiomyopathy [2].

The incidence of DMD-associated cardiomyopathy increases with age, affecting $30 \%$ of 14 -year-olds, $50 \%$ of 18-year-old, and all older patients [3]. However, cardiac dysfunction in DMD children has not been treated seriously enough because more than 30\% of DMD patients have not undergone echocardiography examinations [4]. Recent guidelines have suggested that cardiac imaging should be performed every 2 years (since diagnosis to 10 years of age) or annually (from 10 to 20 years of age) and recommended that echocardiography should be routinely used in the screening and follow-up care of DMD patients [5, 6].

Echocardiography is the most commonly used imaging modality to assess cardiac function. Previous animal studies have usually used echocardiography to assess cardiac function. They revealed that some strain parameters were significantly changed in the DMD dog/mouse model and that strain analysis using speckle-tracking echocardiography (STE) is a feasible and sensitive approach for detecting cardiac dysfunction [7, 8]. STE can quantify myocardial strain and detect subclinical left ventricular dysfunction before left ventricular ejection fraction (LVEF) begins decreasing [9]. Previous STE studies have revealed altered myocardial strain in DMD children with normal fractional shortening and LVEF $[10,11]$. Since then, an increasing number of STE studies have focused on evaluating myocardial strain in DMD children. However, some results of these studies were inconsistent and incomplete and might have limited statistical power because individual studies have relatively small sample sizes and analyze partial myocardial strain parameters. Therefore, meta-analysis aiming to provide a more comprehensive summary to evaluate the value of myocardial strain in children with DMD was carried out in the present study.

\section{Methods}

\section{Search strategy}

Two investigators (GS and JZ) independently searched PubMed, Web of Science, EMBASE, and Google scholar databases from their inception to February 5, 2020 to identify relevant studies. The following search keywords were included: 'Duchenne Muscular Dystrophy', 'echocardiography', and 'strain'. This study only focused on human studies.

\section{Study selection and exclusion}

Original studies were eligible if the following criteria were met: (i) observational study; (ii) the study investigated myocardial strain in DMD children compared to healthy participants; (iii) myocardial strain was measured by STE; and (iv) global longitudinal strain (GLS), global circumferential strain (GCS), and global radial strain (GRS) were defined as the global strain from the left ventricular 16/17-segment model. Average longitudinal strain (LS) was measured using two-dimensional STE at the apical four-chamber view and average circumferential strain (CS) was measured by two-dimensional STE at the papillary muscle short-axis level [12]. LVEF was measured using the biplane modified Simpson's method.

Original studies were ineligible if the following criteria were met: (i) reviews, letters, or case reports; (ii) DMD children with LVEF $<45 \%$ or fractional shortening < 28\%; (iii) invalid analysis, or did not report the data necessary for calculating the mean and standard deviation of myocardial strain; or (iv) did not include a healthy control group. If there were several publications from the same study, the study with the most cases and relevant information was included.

\section{Data extraction and quality assessment}

Data extraction was performed independently by two of the reviewers (GS and JZ). Disagreements were discussed and resolved by consensus or by involving a third reviewer $(\mathrm{XW})$ for adjudication. The extracted clinical data included the first author, year of publication, case number in the DMD and control groups, age, weight, height, heart rate, and country. The extracted echocardiographic data included LVEF, GLS, GCS, GRS, LS, and CS. This study did not contain the analysis of the average radial myocardial strain (from papillary muscle short-axis level) because that radial myocardial strain is not comparable among different ultrasound machines and software packages $[13,14]$.

The Newcastle-Ottawa Scale (NOS) was used to assess the quality of all included studies. The NOS quality score was evaluated as follows: $\leq 5$, low quality; $6-7$, medium quality; and 8-9, high quality. Two authors (XW and XZ) independently assessed the quality of the included studies. Disagreements were resolved by discussion.

\section{Statistical analysis}

The pooled effects were presented as the weighted mean difference (WMD) with 95\% confidence intervals (CIs). Heterogeneity was assessed using the $I^{2}$ statistic. If heterogeneity was not present $\left(P>0.1\right.$ or $\left.I^{2}<50 \%\right)$, a fixed- 
effects model was used to estimate the pooled WMD. Otherwise, a random-effects model was utilized. Subgroup stratified analysis was performed using country ("USA/Europe/Egypt" vs. "China/Korea"), quality of study ("medium quality" vs. "high quality"), method ("two-dimensional STE" vs. "three-dimensional STE"), and machine/software ("GE Vivid E9 with EchoPAC" vs. "Phillps iE33 with Qlab") parameters. Sensitivity analyses were directed to assess the influence of the individual study on the overall estimate. Study effects such as publication bias were evaluated using Egger's tests and a $p$-value $<0.1$ was considered statistically significant for asymmetry. Statistical analyses were performed using Stata (version 14.0; StataCorp, College Station, TX, USA).

\section{Trial sequential analysis (TSA)}

TSA was conducted to maintain a 95\% CI, 20\% relative risk reduction, 5\% level of type I error and 20\% level of type II error (a power of 80\%). When the cumulative Z-curve crossed the trial sequential monitoring boundary or exceeded the required information size line, it was considered to be an indicator of sufficient and firm evidence, with no further studies required. Otherwise, additional studies were needed. Trial Sequential Analysis (version 0.9.5.10 Beta) was used in this study.

\section{Results}

\section{Description of the included studies}

A total of 264 potentially relevant publications from four databases, including 26 from PubMed, 69 from Embase, 45 from Web of Science, and 124 from Google scholar (Fig. 1) were identified and reviewed. After application of the inclusion and exclusion criteria, eight observational studies were identified [10, 11, 15-20].

The baseline characteristics of the eight included studies are shown in Table 1. These studies were published between 2013 and 2019. In total, 269 DMD children and 299 healthy participants were included. Male children were the main subjects of four studies. DMD children had a mean age of $9.34 \pm 3.62$ years, compared to $10.45 \pm 5.88$ years in the control group. Four studies were conducted in USA/Europe/Egypt and included predominantly Caucasian patients. The other four studies were conducted in China/Korea, which are mainly East Asian. The NOS score ranged from 7 to 9 , indicating that low-quality studies were not involved.

Measurement of GLS, GCS, LS, and CS using 2D STE was feasible in all participants of the control group. $100 \%(85 / 85)$ of GLS, $100 \%$ (19/19) of GCS, $94 \%(49 / 52)$ of LS, and $96 \%$ of $(145 / 151)$ of CS could be measured by 2D STE in DMD patients. Measurement of GLS, GCS, and GRS using 3D STE was feasible in all subjects of the DMD and control groups. Five studies contained the intraobserver and interobserver variability test for myocardial strain $[10,11,16-18]$. The intraobserver and

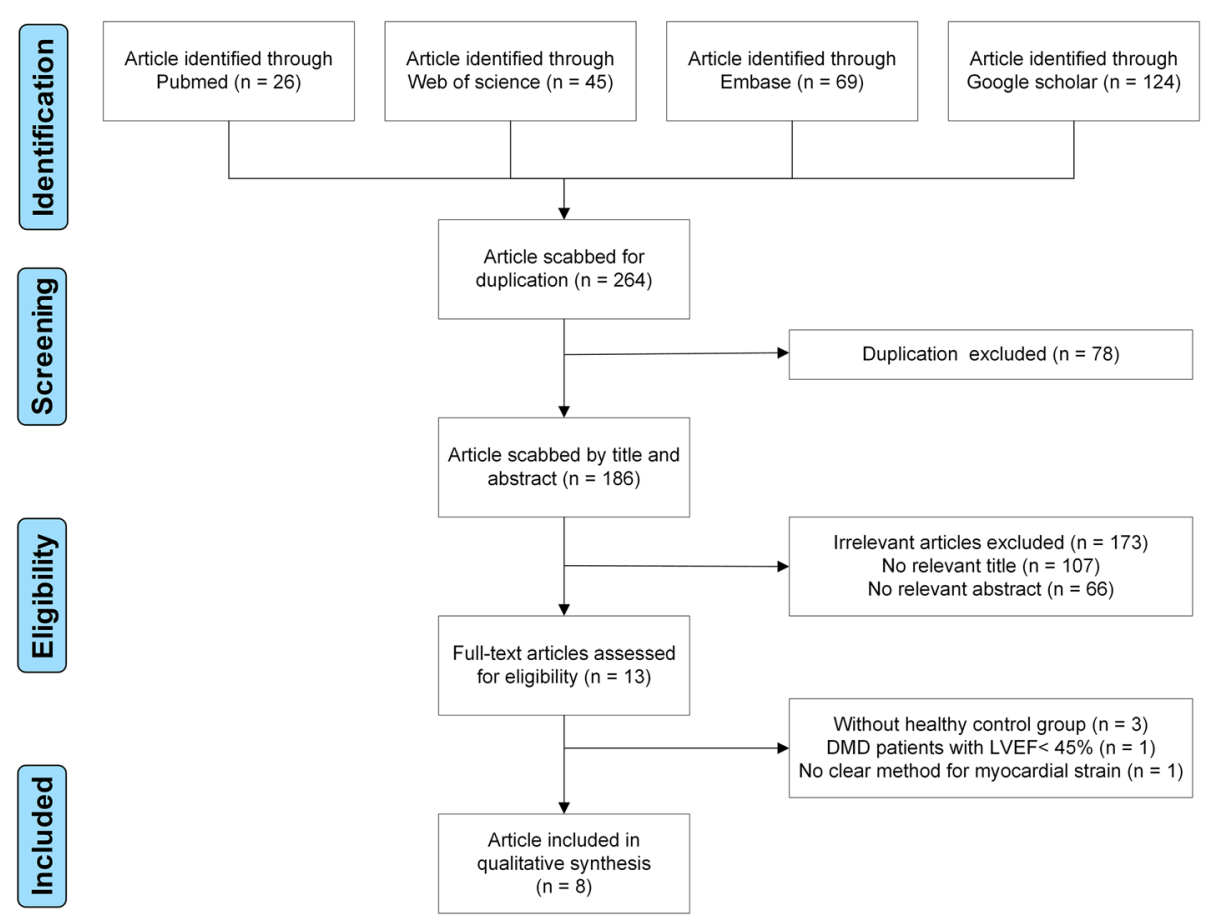

Fig. 1 Flow-chart of study selection 
Table 1 Characteristics of included studies

\begin{tabular}{|c|c|c|c|c|c|c|c|c|c|c|}
\hline \multirow{2}{*}{$\begin{array}{l}\text { First } \\
\text { author }\end{array}$} & \multirow[t]{2}{*}{ Year } & \multirow{2}{*}{$\begin{array}{l}\text { Number } \\
\text { of cases } \\
\text { (DMD/ } \\
\text { control) }\end{array}$} & \multirow{2}{*}{$\begin{array}{l}\text { Male } \\
\text { (DMD/ } \\
\text { control, \%) }\end{array}$} & \multicolumn{2}{|l|}{ Age (year) } & \multirow{2}{*}{$\begin{array}{l}\text { Weight } \\
\text { (DMD/ } \\
\text { control, } \\
\text { kg) }\end{array}$} & \multirow{2}{*}{$\begin{array}{l}\text { Height } \\
\text { (DMD/ } \\
\text { control, } \\
\mathrm{cm})\end{array}$} & \multirow{2}{*}{$\begin{array}{l}\text { Heart rate } \\
\text { (DMD/ } \\
\text { control, } \\
\text { bpm) }\end{array}$} & \multirow[t]{2}{*}{ Country } & \multirow{2}{*}{$\begin{array}{l}\text { NOS } \\
\text { score }\end{array}$} \\
\hline & & & & DMD & Control & & & & & \\
\hline Ryan & 2013 & $63 / 61$ & $100 \% / 100 \%$ & $5.6 \pm 0.2$ & $5.2 \pm 0.2$ & $19.7 / 21.0$ & $106.7 / 111.4$ & $100.8 / 87.7$ & USA & 9 \\
\hline Spurney & 2015 & $35 / 33$ & NR & $13.0 \pm 2.0$ & $13.0 \pm 3.0$ & NR & NR & $92.0 / 67.0$ & USA & 8 \\
\hline Taqatqa & 2016 & $19 / 16$ & $100 \% / 100 \%$ & $11.0 \pm 3.7$ & $12.6 \pm 3.1$ & $38.0 / 54.4$ & $136.0 / 164.0$ & $98 / 69$ & USA & 7 \\
\hline Cho & 2018 & $13 / 26$ & NR & $9.7 \pm 2.2$ & $9.7 \pm 2.2$ & NR & NR & $91 / 80$ & Korea & 7 \\
\hline Yu & 2019 & $56 / 31$ & NR & $8.8 \pm 1.9$ & $8.4 \pm 1.8$ & 27.9/28.9 & 128.6/132.1 & NR & China & 8 \\
\hline Wang & 2019 & $30 / 30$ & NR & $7.8 \pm 1.8$ & $8.3 \pm 1.7$ & $27.7 / 28.1$ & $122.6 / 126.6$ & $89 / 91$ & China & 6 \\
\hline Amedro & 2019 & $36 / 72$ & 100\%/100\% & $11.0 \pm 3.8$ & $10.0 \pm 3.5$ & $36.8 / 37.9$ & 134.9/143.7 & $96 / 75$ & Europe & 9 \\
\hline Habib & 2019 & $17 / 30$ & $82 \% / 83 \%$ & $14.5 \pm 3.7$ & $22.3 \pm 9.5$ & $55.4 / 54.9$ & $110.0 / 146.0$ & $92 / 84$ & Egypt & 6 \\
\hline
\end{tabular}

DMD Duchenne muscular dystrophy, NOS Newcastle-Ottawa Scale, NR No reported

interobserver variability values were low in those five studies.

\section{The difference in myocardial strain between DMD and control groups}

Pooled analysis indicated that LVEF was unchanged in the DMD group compared to the control group (WMD $=-1.00,95 \%$ CI: $-2.70-0.70, P=0.249)$ (Table 2, Fig. 2). STE revealed that GLS, GCS, LS, and CS had a significant decrease in DMD children compared to the control group (WMD $=4.17,95 \% \mathrm{CI}$ : 3.03-5.32; WMD = 3.98, 95\% CI: $0.29-7.68$; WMD $=4.18,95 \%$ CI: $2.75-$ 5.62; and $\mathrm{WMD}=4.90,95 \%$ CI: $2.38-7.43$, respectively; all $P<0.05$ ) (Figs. 3, 4, 5, 6 and 7). However, GRS was unchanged in the DMD group compared to the control group (WMD $=-4.33$, 95\% CI: $-9.53-0.87, P=0.103$ ).

\section{Subgroup analysis}

To investigate the possible sources of GLS heterogeneity $\left(I^{2}=62.0 \%, P=0.010\right)$ as a main echocardiographic parameter, subgroup analysis was carried out and indicated that significant results were observed in all subgroup analyses (Table 3).

\section{Sensitivity analysis and publication bias}

To evaluate the robustness of the results, sensitivity analyses were performed by sequentially removing each study. As a result, no apparent change occurred in the GLS, LS, CS, and LVEF when an individual study was omitted, confirming that the results were stable (Table 2). No publication bias was detected among studies focused on the GLS, GRS, or LVEF, which was confirmed by the Egger's tests (Table 2).

\section{Trial sequential analysis}

The cumulative Z-curve for GLS, LS, and CS passed both the traditional boundary and trial sequential monitoring boundary, suggesting sufficient evidence for such a difference between the DMD and control groups (Fig. 8, and Figure S1-S2 in Supplement file).

The cumulative Z-curve for GCS crossed the traditional boundary, but GRS did not. Neither GCS nor GRS reached the trial sequential monitoring boundary or required information size line, suggesting that more studies are needed for further analysis (Figure S3-S4 in Supplement file).

Table 2 The meta-analysis of myocardial strain and LVEF between DMD and control groups

\begin{tabular}{|c|c|c|c|c|c|c|c|c|}
\hline \multirow[t]{2}{*}{ Parameter } & \multicolumn{2}{|l|}{ Test of difference } & \multicolumn{2}{|c|}{ Test of Heterogeneity } & \multirow{2}{*}{$\begin{array}{l}\text { Statistical } \\
\text { Model }\end{array}$} & \multirow{2}{*}{$\begin{array}{l}\text { Test of } \\
\text { Publication } \\
\text { Bias Egger's } \\
P \text {-value }\end{array}$} & \multicolumn{2}{|l|}{ Sensitivity Analysis } \\
\hline & $\overline{\text { WMD }(95 \% \mathrm{Cl})}$ & $P$ value & $\overline{P^{2}(\%)}$ & $P$ value & & & Odds Ratio $(95 \% \mathrm{Cl})_{\text {min }}$ & Odds Ratio $(95 \% \mathrm{Cl})_{\max }$ \\
\hline$\overline{G L S}$ & $4.17(3.03-5.32)$ & $<0.001$ & 62.0 & 0.010 & Random & 0.498 & $3.81(2.76-4.86)$ & $4.56(3.75-5.36)$ \\
\hline GCS & $3.98(0.29-7.68)$ & 0.034 & 92.2 & $<0.001$ & Random & 0.023 & $1.93(-0.23-3.88)$ & $5.61(0.32-10.90)$ \\
\hline GRS & $-4.33(-9.53-0.87)$ & 0.103 & 72.2 & 0.027 & Random & 0.525 & $-6.35(-12.82-0.12)$ & $-1.61(-4.72-1.51)$ \\
\hline LS & $4.18(2.75-5.62)$ & $<0.001$ & 35.0 & 0.215 & Fixed & - & $3.60(1.89-5.31)$ & $5.60(2.94-8.26)$ \\
\hline CS & $4.90(2.38-7.43)$ & $<0.001$ & 85.6 & $<0.001$ & Random & 0.085 & $3.74(1.65-5.82)$ & $6.05(3.17-8.92)$ \\
\hline LVEF & $-1.00(-2.70-0.70)$ & 0.249 & 76.5 & $<0.001$ & Random & 0.651 & $-1.45(-3.19-0.28)$ & $-0.37(-1.94-1.19)$ \\
\hline
\end{tabular}

Cl confidence interval, CS circumferential strain, DMD Duchenne muscular dystrophy, GCS global circumferential strain, GLS global longitudinal strain, GRS global radial strain, $L S$ longitudinal strain, $L V E F$ left ventricular ejection fraction, WMD weighted mean difference. Significant results are marked in bold 


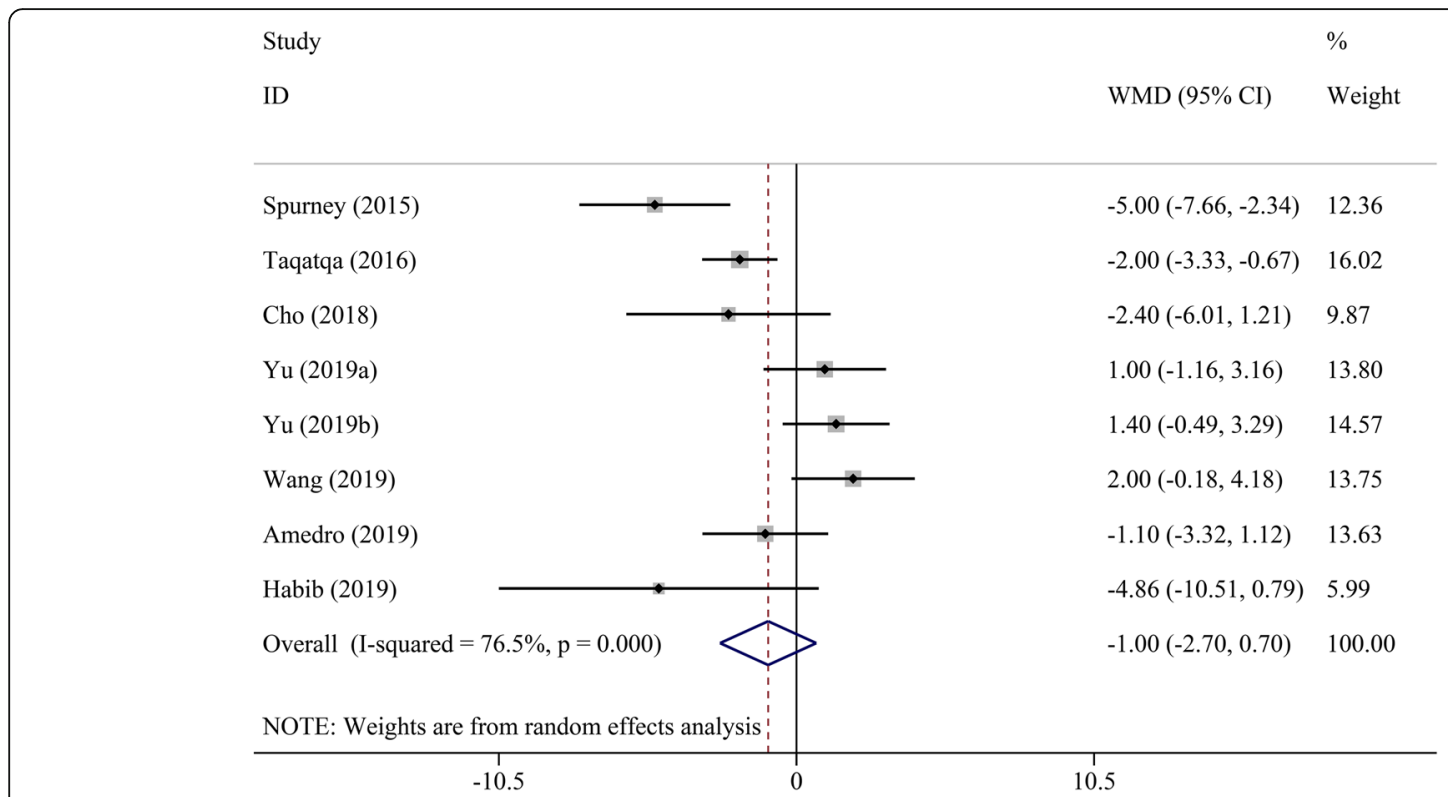

Fig. 2 The meta-analysis of WMD in LVEF between DMD and control groups. Cl, confidence interval; DMD, Duchenne muscular dystrophy; LVEF, left ventricular ejection fraction; WMD, weighted mean difference

\section{Discussion}

This is the first meta-analysis comprehensively summarizing the early changes in myocardial strain in DMD children. In this meta-analysis, GLS served as an explicit index for early detection, which was confirmed by sensitivity analysis, publication bias test, and TSA. CS and LS were affected by the small number of involved studies, which can decrease their certainty. TSA indicated that
GCS and GRS needed more research data to reach a firm conclusion.

Most DMD patients develop cardiomyopathy by the age of 20 years [21]. Some DMD children with cardiac involvement were undertreated or not being treated with cardiac-specific medicines in clinical practice [4]. Although DMD cannot be cured, some medicines may modify the course of cardiomyopathy and be beneficial

\begin{tabular}{|c|c|c|}
\hline & Study & $\%$ \\
\hline & ID & Weight \\
\hline & Taqatqa (2016) & 9.62 \\
\hline & Cho (2018) & 11.82 \\
\hline & Yu (2019a) & 11.53 \\
\hline & Yu (2019b) & 12.74 \\
\hline & Wang (2019) & 13.86 \\
\hline & Amedro (2019) & 15.69 \\
\hline & Habib (2019a) & 12.66 \\
\hline & Habib (2019b) & 12.09 \\
\hline & Overall $(\mathrm{I}$-squared $=62.0 \%, \mathrm{p}=0.010)$ & 100.00 \\
\hline & NOTE: Weights are from random effects analysis & \\
\hline & -8.54 & \\
\hline
\end{tabular}




\section{Study}

ID

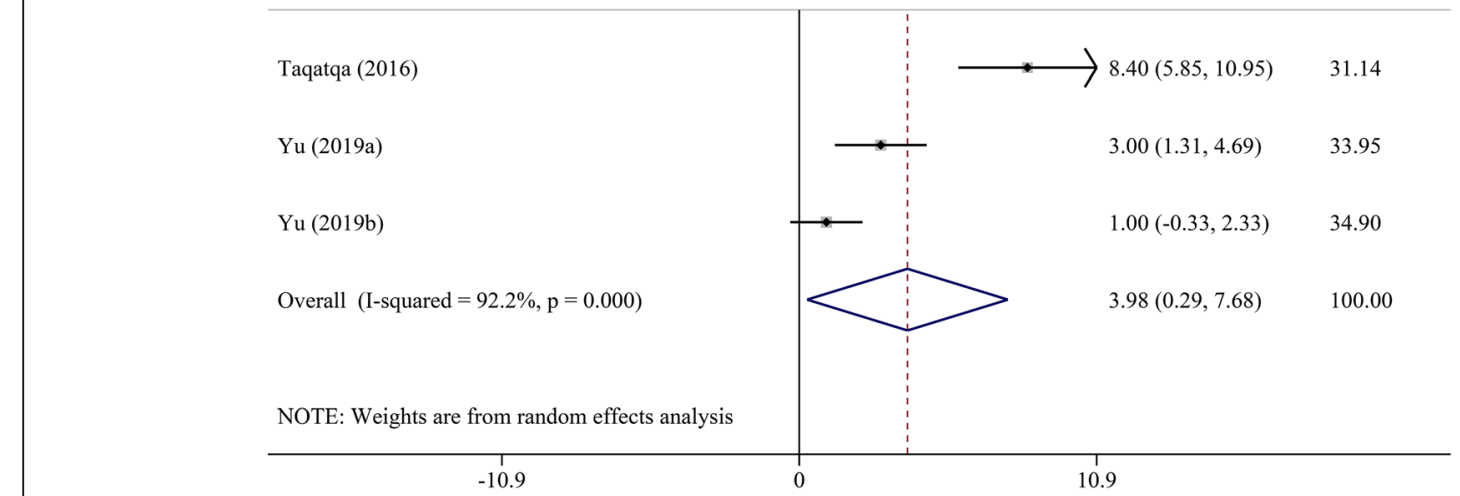

WMD $(95 \% \mathrm{CI}) \quad$ Weight

Fig. 4 The meta-analysis of WMD in GCS between DMD and control groups. Cl, confidence interval; DMD, Duchenne muscular dystrophy; GCS, global circumferential strain; WMD, weighted mean difference

for delaying progression of heart failure [22-24]. The onset of symptoms and reduced LVEF were the important factors affecting the timing of medical treatment [5, 6]. Unfortunately, the patients were often beyond the point of reversible injury [25]. The reasons were the following: (i) cardiac dysfunction is progressing very slightly and limited daily activities in DMD children may cover up their initial symptoms; (ii) as the most common index to assess left ventricle contraction, LVEF usually fails to detect early cardiac systolic dysfunction [26]. Hence, detection of early pre-symptomatic cardiac involvement using a new index in DMD children is urgently needed.
Before symptoms appeared and LVEF decreased, the myocardial strain has emerged as a promising parameter of subclinical myocardial dysfunction. A recent review stated that myocardial strain can be assessed via cardiac magnetic resonance or echocardiography [27]. Cardiac magnetic resonance has been used to measure strain. However, it may be challenging in patients with DMD, especially in young children who cannot cooperate during the examination [28]. In the past, echocardiographers measured myocardial strain using tissue Doppler imaging, which is limited by poor echocardiographic windows and the probe angle [27]. STE is the preferred technique for measuring myocardial strain to provide a

\section{Study}

ID

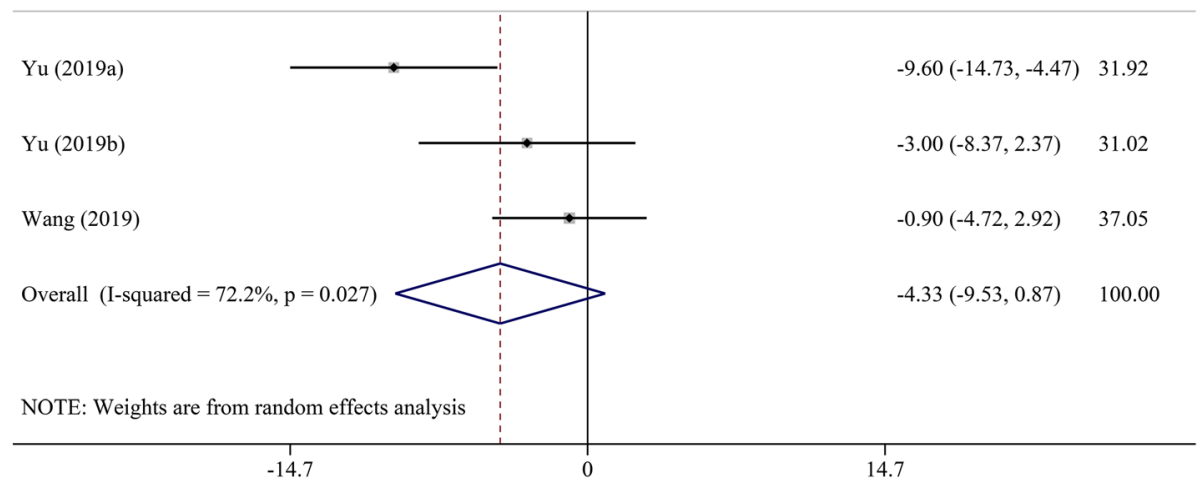

$\%$

WMD $(95 \% \mathrm{Cl}) \quad$ Weight

Fig. 5 The meta-analysis of WMD in GRS between DMD and control groups. Cl, confidence interval; DMD, Duchenne muscular dystrophy; GRS, global radial strain; WMD, weighted mean difference 


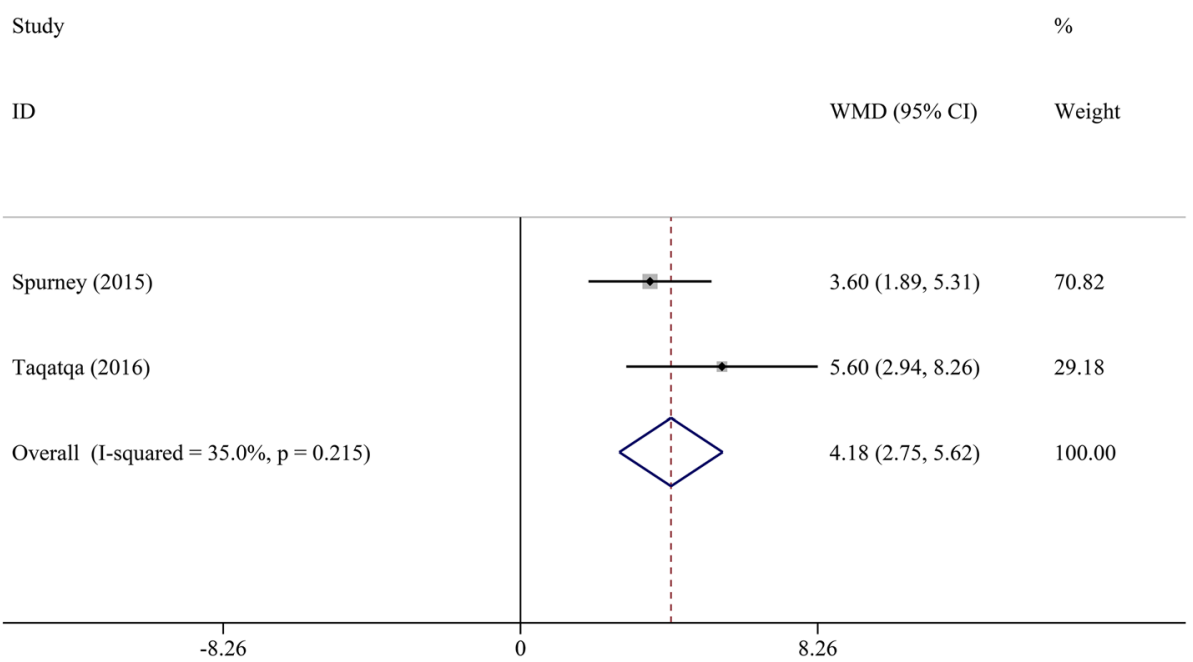

Fig. 6 The meta-analysis of WMD in LS between DMD and control groups. Cl, confidence interval; DMD, Duchenne muscular dystrophy; LS, longitudinal strain; WMD, weighted mean difference

rapid, precise, and objective assessment of the left heart function $[29,30]$. The high repeatability of STE is due to its independence on the angle, which allows to measure only the active contraction, avoiding the tethering effect of noncontractile tissue.

STE can assess the global or segmental myocardial strain. However, segmental strain in DMD children has high variability. For segmental longitudinal strain, Mertens et al. study revealed that anterolateral segmental longitudinal strain is more severely impaired [31]. Taqatqa et al. showed that apical segmental longitudinal strain is more pronounced [15]. Furthermore, Cho et al. found that basal segmental longitudinal strain is serious
[16]. Finally, Amedro et al. revealed that segmental longitudinal strain in most segments decreased in DMD children [18]. Therefore, meta-analysis in the present study focused on the global/average myocardial strain. In these five types of strain, GLS provided the best evidence for early detection of myocardial strain in DMD children based on the existing data. This ability to detect subclinical myocardial dysfunction in patients with normal LVEF was consistent with other research findings [32, 33]. According to the result by Yu et al., GLS has an $82.1 \%$ sensitivity to identify DMD when using $-20.5 \%$ as a cutoff value [17]. GLS did not only detect this subtle left ventricular systolic dysfunction, but also played a

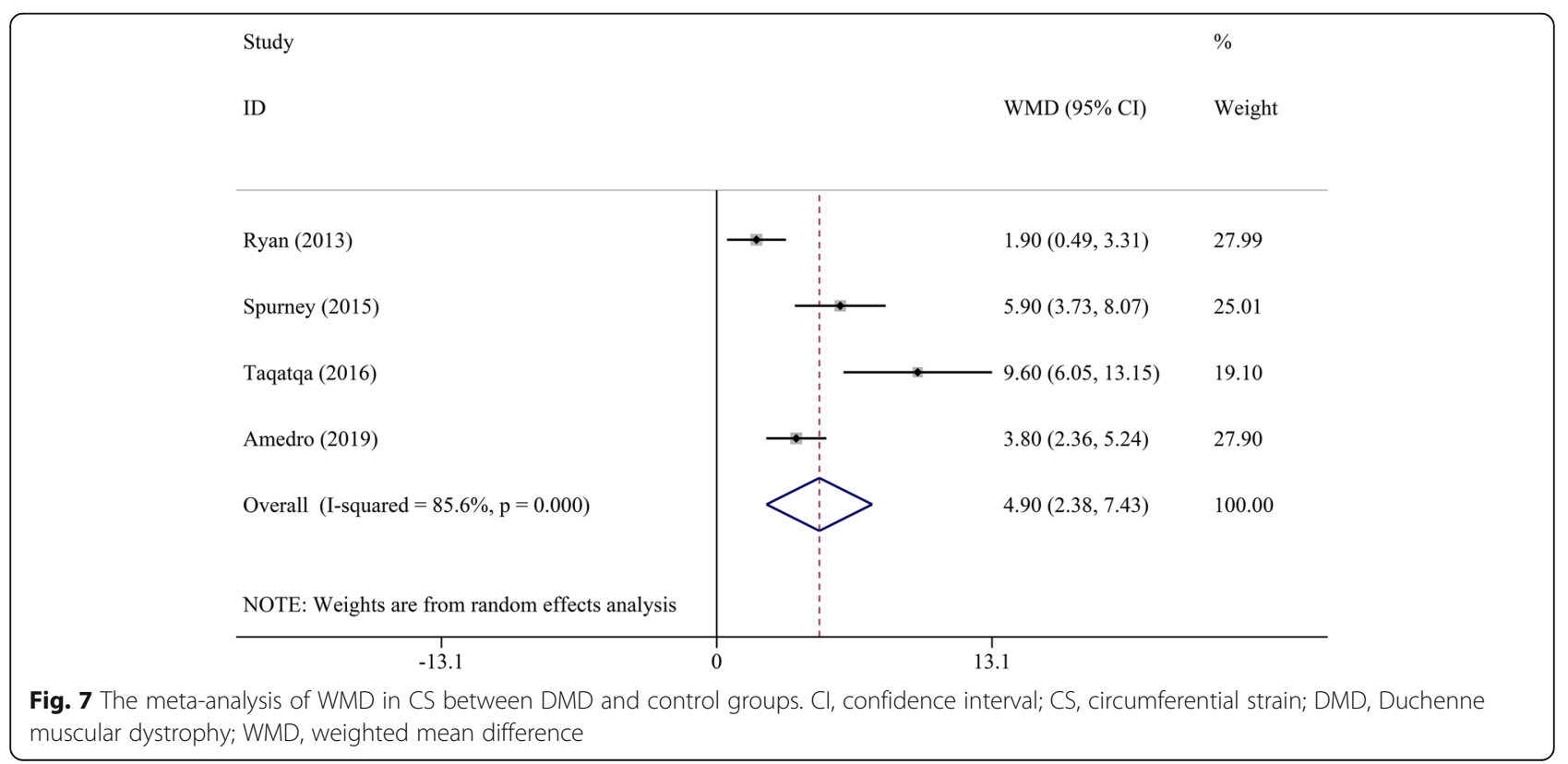


Table 3 Subgroup analyses of GLS between DMD and control groups

\begin{tabular}{|c|c|c|c|c|c|}
\hline & \multirow{2}{*}{$\begin{array}{l}\text { Number } \\
\text { of } \\
\text { studies }\end{array}$} & \multicolumn{2}{|l|}{ Test of difference } & \multicolumn{2}{|c|}{ Test of Heterogeneity } \\
\hline & & $\overline{\text { WMD }(95 \% \mathrm{Cl})}$ & $P$ value & $\bar{P}(\%)$ & $P$ value \\
\hline \multicolumn{6}{|l|}{ Country } \\
\hline USA/Europe/Egypt & 4 & $5.01(3.73-6.29)$ & $<0.001$ & 40.5 & 0.169 \\
\hline China/Korea & 4 & $3.28(1.63-4.93)$ & $<0.001$ & 62.4 & 0.047 \\
\hline \multicolumn{6}{|l|}{ Quality of study } \\
\hline Medium quality & 5 & $4.89(3.78-6.00)$ & $<0.001$ & 28.3 & 0.233 \\
\hline High quality & 3 & $3.04(1.04-5.05)$ & 0.003 & 71.5 & 0.030 \\
\hline \multicolumn{6}{|l|}{ Method } \\
\hline Two-dimensional STE & 4 & $4.90(3.62-6.19)$ & $<0.001$ & 40.1 & 0.171 \\
\hline Three-dimensional STE & 4 & $3.41(1.64-5.17)$ & $<0.001$ & 67.8 & 0.025 \\
\hline \multicolumn{6}{|l|}{ Machine/software } \\
\hline GE Vivid E9 with EchoPAC & 7 & $4.07(2.83-5.31)$ & $<0.001$ & 66.1 & 0.007 \\
\hline Philips iE33 with Qlab & 1 & $5.20(2.51-7.89)$ & $<0.001$ & - & - \\
\hline
\end{tabular}

Cl confidence interval, GLS global longitudinal strain, STE speckle tracking echocardiography, WMD weighted mean difference

key role in detecting other cardiomyopathies [34, 35]. The $3 \mathrm{D}$ and 2D global strain values correlated well in both normally and abnormally contracting hearts in children [36-38]. However, stratified analysis using echocardiography methods was still used, considering the possible differences arising from the inclusion of both 2D and 3D strains in DMD children. No differences were present between 3D and 2D GLS subgroups. GLS measured by STE has its own limitation, as the quality of the echocardiographic images decreases with increasing age in DMD children and young adults [39]. Furthermore, the lack of GLS accepted normal reference also limited its further clinical applications.
There are several limitations in this study. First, older children ( $>8$ years old) had a lower GLS than younger children ( $\leq 8$ years old) [17]. However, the data were not sufficient to perform subgroup analysis by age in this meta-analysis. Second, global area strain was not analyzed in this meta-analysis due to insufficient sample size.

\section{Conclusion}

GLS can be useful for early detection of left ventricle myocardial dysfunction in children with DMD. The role of other myocardial strains in DMD children needs further study.

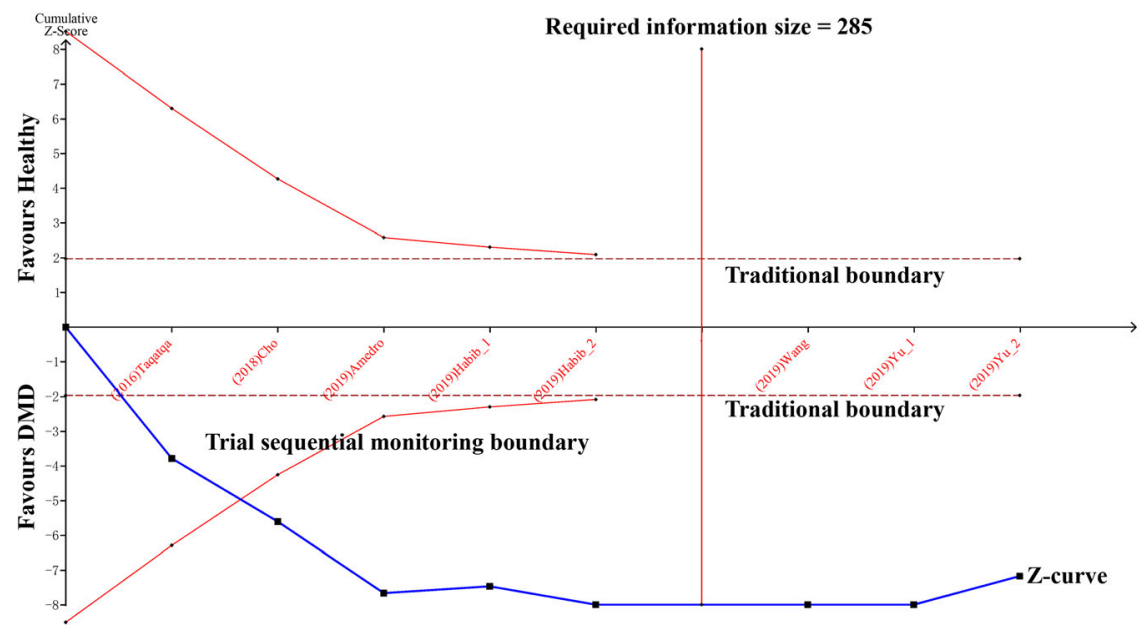

Fig. 8 Comparison of the GLS between DMD and control groups by TSA. DMD, Duchenne muscular dystrophy; GLS, global longitudinal strain; TSA, trial sequential analysis 


\section{Supplementary information}

Supplementary information accompanies this paper at https://doi.org/10. 1186/s12947-020-00209-y.

Additional file 1: Figure S1. Comparison of the LS between DMD and control groups by TSA. DMD, Duchenne muscular dystrophy; LS, longitudinal strain; TSA, trial sequential analysis. Figure S2 Comparison of the CS between DMD and control groups by TSA. CS, circumferential strain; DMD, Duchenne muscular dystrophy; TSA, trial sequential analysis. Figure S3 Comparison of the GCS between DMD and control groups by TSA. DMD, Duchenne muscular dystrophy; GCS, global circumferential strain; TSA, trial sequential analysis. Figure S4 Comparison of the GRS between DMD and control groups by TSA. DMD, Duchenne muscular dystrophy; GRS, global radial strain; TSA, trial sequential analysis.

\section{Abbreviations}

Cls: Confidence intervals; CS: Circumferential strain; DMD: Duchenne muscular dystrophy; GCS: Global circumferential strain; GLS: Global longitudinal strain; GRS: Global radial strain; LS: Longitudinal strain; LVEF: Left ventricular ejection fraction; NOS: Newcastle-Ottawa scale; STE: Speckletracking echocardiography; TSA: Trial sequential analysis; WMD: Weighted mean difference

\section{Acknowledgments}

None.

\section{Authors' contributions}

GS designed the study, collected the data and drafted the manuscript. JZ and XW collected the data and analyzed the data. XZ collected the data and analyzed the data. FS analyzed the data. $X Y$ designed the study and drafted the manuscript. All authors read and approved the final manuscript.

\section{Funding}

This research is supported by a grant from the 2018 Liaoning Provinicial Natural Science Key Project of China (no. 20180530064); and the Young Scientists Fund of the National Natural Science Foundation of China (no. 81901763).

\section{Availability of data and materials}

The datasets used and/or analyzed during the current study are available from the corresponding author on reasonable request.

\section{Ethics approval and consent to participate}

Not applicable.

\section{Consent for publication}

Not applicable.

\section{Competing interests}

The authors declare that they have no competing interests.

Received: 23 April 2020 Accepted: 7 July 2020

Published online: 10 July 2020

\section{References}

1. Mah JK, Korngut L, Dykeman J, Day L, Pringsheim T, Jette N. A systematic review and meta-analysis on the epidemiology of Duchenne and Becker muscular dystrophy. Neuromuscul Disord. 2014;24(6):482-91.

2. Mercuri E, Bonnemann CG, Muntoni F. Muscular dystrophies. Lancet. 2019; 394(10213):2025-38

3. Muntoni F. Cardiac complications of childhood myopathies. J Child Neurol. 2003;18(3):191-202.

4. Spurney C, Shimizu R, Morgenroth LP, Kolski H, Gordish-Dressman H, Clemens PR, et al. Cooperative international neuromuscular research group Duchenne natural history study demonstrates insufficient diagnosis and treatment of cardiomyopathy in Duchenne muscular dystrophy. Muscle Nerve. 2014:50(2):250-6.

5. Pinto YM, Elliott PM, Arbustini E, Adler Y, Anastasakis A, Bohm M, et al. Proposal for a revised definition of dilated cardiomyopathy, hypokinetic non-dilated cardiomyopathy, and its implications for clinical practice: a position statement of the ESC working group on myocardial and pericardial diseases. Eur Heart J. 2016;37(23):1850-8.

6. Feingold B, Mahle WT, Auerbach S, Clemens P, Domenighetti AA, Jefferies $J$, et al. Management of Cardiac Involvement Associated with neuromuscular diseases: a scientific statement from the American Heart Association. Circulation. 2017;136(13):e200-31.

7. Li Z, Li Y, Zhang L, Zhang X, Sullivan R, Ai X, et al. Reduced myocardial Reserve in Young $X$-linked muscular dystrophy mice diagnosed by twodimensional strain analysis combined with stress echocardiography. J Am Soc Echocardiogr. 2017;30(8):815-27 e819.

8. Ghaleh B, Barthelemy I, Sambin L, Bize A, Hittinger L, Blot S, et al. Alteration in left ventricular contractile function develops in puppies with Duchenne muscular dystrophy. J Am Soc Echocardiogr. 2020;33(1):120-9 e121.

9. Kalam K, Otahal P, Marwick TH. Prognostic implications of global LV dysfunction: a systematic review and meta-analysis of global longitudinal strain and ejection fraction. Heart. 2014;100(21):1673-80.

10. Ryan TD, Taylor MD, Mazur W, Cripe LH, Pratt J, King EC, et al. Abnormal circumferential strain is present in young Duchenne muscular dystrophy patients. Pediatr Cardiol. 2013;34(5):1159-65.

11. Spurney CF, McCaffrey FM, Cnaan A, Morgenroth LP, Ghelani SJ, GordishDressman $\mathrm{H}$, et al. Feasibility and reproducibility of echocardiographic measures in children with muscular dystrophies. J Am Soc Echocardiogr. 2015;28(8):999-1008.

12. Levy PT, Machefsky A, Sanchez AA, Patel MD, Rogal S, Fowler S, et al. Reference ranges of left ventricular strain measures by two-dimensional speckle-tracking echocardiography in children: a systematic review and meta-analysis. J Am Soc Echocardiogr. 2016;29(3):209-25 e206.

13. Koopman LP, Slorach C, Hui W, Manlhiot C, McCrindle BW, Friedberg MK, et al. Comparison between different speckle tracking and color tissue Doppler techniques to measure global and regional myocardial deformation in children. J Am Soc Echocardiogr. 2010;23(9):919-28.

14. Koopman LP, Slorach C, Manlhiot C, McCrindle BW, Jaeggi ET, Mertens L, et al. Assessment of myocardial deformation in children using digital imaging and Communications in Medicine (DICOM) data and vendor independent speckle tracking software. J Am Soc Echocardiogr. 2011;24(1):37-44.

15. Taqatqa A, Bokowski J, Al-Kubaisi M, Khalil A, Miranda C, Alaksham H, et al. The use of speckle tracking echocardiography for early detection of myocardial dysfunction in patients with Duchenne muscular dystrophy. Pediatr Cardiol. 2016;37(8):1422-8.

16. Cho MJ, Lee JW, Lee J, Shin YB. Evaluation of early left ventricular dysfunction in patients with Duchenne muscular dystrophy using twodimensional speckle tracking echocardiography and tissue Doppler imaging. Pediatr Cardiol. 2018;39(8):1614-9.

17. Yu HK, Xia B, Liu X, Han CX, Chen WL, Li ZH. Initial application of threedimensional speckle-tracking echocardiography to detect subclinical left ventricular dysfunction and stratify cardiomyopathy associated with Duchenne muscular dystrophy in children. Int J Card Imaging. 2019:35(1):67-76.

18. Amedro P, Vincenti M, De La Villeon G, Lavastre K, Barrea C, Guillaumont S, et al. Speckle-tracking echocardiography in children with Duchenne muscular dystrophy: a prospective multicenter controlled cross-sectional study. J Am Soc Echocardiogr. 2019;32(3):412-22.

19. Wang WP, Zhao M, Li WK. The application of three-dimensional speckle tracking echocardiography technique in children with Duchenne muscular dystrophy. J Cardiovasc Pulmon Dis. 2019;38(3):290-2.

20. Habib SA, Mohie El Din TM. Early detection of left ventricular involvement in patients with Duchenne's and Becker's muscular dystrophy. Al-Azhar Assiut Medical Journal. 2019;17(4):409-16.

21. van Westering TL, Betts CA, Wood MJ. Current understanding of molecular pathology and treatment of cardiomyopathy in duchenne muscular dystrophy. Molecules. 2015;20(5):8823-55.

22. Allen HD, Flanigan KM, Thrush PT, Dvorchik I, Yin H, Canter C, et al. A randomized, double-blind trial of lisinopril and losartan for the treatment of cardiomyopathy in duchenne muscular dystrophy. PLoS Curr. 2013;5:1-13.

23. Duboc D, Meune C, Pierre B, Wahbi K, Eymard B, Toutain A, et al. Perindopri preventive treatment on mortality in Duchenne muscular dystrophy: 10 years' follow-up. Am Heart J. 2007;154(3):596-602.

24. Bourke JP, Bueser T, Quinlivan R. Interventions for preventing and treating cardiac complications in Duchenne and Becker muscular dystrophy and X-linked dilated cardiomyopathy. Cochrane Database Syst Rev. 2018;10:CD009068.

25. Manzur AY, Kinali M, Muntoni F. Update on the management of Duchenne muscular dystrophy. Arch Dis Child. 2008;93(11):986-90. 
26. Hor KN, Wansapura J, Markham LW, Mazur W, Cripe LH, Fleck R, et al. Circumferential strain analysis identifies strata of cardiomyopathy in Duchenne muscular dystrophy: a cardiac magnetic resonance tagging study. J Am Coll Cardiol. 2009;53(14):1204-10.

27. Power LC, O'Grady GL, Hornung TS, Jefferies C, Gusso S, Hofman PL. Imaging the heart to detect cardiomyopathy in Duchenne muscular dystrophy: a review. Neuromuscul Disord. 2018;28(9):717-30.

28. Hor KN, Kissoon N, Mazur W, Gupta R, Ittenbach RF, Al-Khalidi HR, et al. Regional circumferential strain is a biomarker for disease severity in duchenne muscular dystrophy heart disease: a cross-sectional study. Pediatr Cardiol. 2015;36(1):111-9.

29. Song G, Liu J, Ren W, Qiao W, Zhang J, Zhan Y, et al. Reversible changes of left atrial function during pregnancy assessed by two-dimensional speckle tracking echocardiography. PLoS One. 2015;10(5):e0125347.

30. Edvardsen T, Helle-Valle T, Smiseth OA. Systolic dysfunction in heart failure with normal ejection fraction: speckle-tracking echocardiography. Prog Cardiovasc Dis. 2006;49(3):207-14.

31. Mertens L, Ganame J, Claus P, Goemans N, Thijs D, Eyskens B, et al. Early regional myocardial dysfunction in young patients with Duchenne muscular dystrophy. J Am Soc Echocardiogr. 2008;21(9):1049-54.

32. Stokke TM, Hasselberg NE, Smedsrud MK, Sarvari SI, Haugaa KH, Smiseth OA, et al. Geometry as a confounder when assessing ventricular systolic function: comparison between ejection fraction and strain. J Am Coll Cardiol. 2017:70(8):942-54.

33. Luis SA, Chan J, Pellikka PA. Echocardiographic assessment of left ventricular systolic function: an overview of contemporary techniques, including speckle-tracking echocardiography. Mayo Clin Proc. 2019;94(1):125-38.

34. Ma C, Chen J, Yang J, Tang L, Chen X, Li N, et al. Quantitative assessment of left ventricular function by 3 -dimensional speckle-tracking echocardiography in patients with chronic heart failure: a meta-analysis. J Ultrasound Med. 2014;33(2):287-95.

35. Zito C, Longobardo L, Citro R, Galderisi M, Oreto L, Carerj ML, et al. Ten years of $2 \mathrm{D}$ longitudinal strain for early myocardial dysfunction detection: a clinical overview. Biomed Res Int. 2018;2018:8979407.

36. Trache T, Stobe S, Tarr A, Pfeiffer D, Hagendorff A. The agreement between 3D, standard 2D and triplane 2D speckle tracking: effects of image quality and 3D volume rate. Echo Res Pract. 2014;1 (2):71-83.

37. Balasubramanian S, Punn R, Smith SN, Houle H, Tacy TA. Left ventricular systolic myocardial deformation: a comparison of two- and threedimensional echocardiography in children. J Am Soc Echocardiogr. 2017; 30(10):974-83.

38. Wisotzkey BL, Soriano BD, Buddhe S. Comparison of two-dimensional and three-dimensional echocardiographic strain in children with CHD. Cardiol Young. 2017;27(8):1557-65

39. Power A, Poonja S, Disler D, Myers K, Patton DJ, Mah JK, et al. Echocardiographic image quality deteriorates with age in children and young adults with Duchenne muscular dystrophy. Front Cardiovasc Med. 2017:4:82

\section{Publisher's Note}

Springer Nature remains neutral with regard to jurisdictional claims in published maps and institutional affiliations.

Ready to submit your research? Choose BMC and benefit from:
- fast, convenient online submission
- thorough peer review by experienced researchers in your field
- rapid publication on acceptance
- support for research data, including large and complex data types
- gold Open Access which fosters wider collaboration and increased citations
- maximum visibility for your research: over 100M website views per year
At BMC, research is always in progress.
Learn more biomedcentral.com/submissions

